\title{
The Potential of Bamboo in the Design of Polymer Composites
}

\author{
Patrícia Santos Delgado, Sebastiana Luiza Bragança Lana, Eliane Ayres ${ }^{\text {a*, }}$
} Patrícia Oliveira Santiago Patrício ${ }^{\mathrm{b}}$, Rodrigo Lambert Oréfice ${ }^{\mathrm{c}}$

\author{
${ }^{a}$ Department of Materials, Technologies and Processes, School of Design, \\ Minas Gerais State University - UEMG, Av. Antônio Carlos, 7545, \\ São Luiz, CEP 31270-010, Belo Horizonte, MG, Brazil \\ ${ }^{\mathrm{b}}$ Department of Chemistry, Federal Center of Technological Education - CEFET-MG, \\ Av. Amazonas, 5253, Nova Suíça, CEP 30421-169, Belo Horizonte, MG, Brazil \\ ${ }^{\mathrm{C}}$ Department of Metallurgical and Materials Engineering, Escola de Engenharia, \\ Federal University of Minas Gerais - UFMG, Av. Antônio Carlos, 6627, sala 2233, Pampulha, \\ CEP 31279-901, Belo Horizonte, MG, Brazil
}

Received: November 7, 2011; Revised: May 7, 2012

\begin{abstract}
Bamboo is an alternative sustainable material for use in product design and has been incorporated into the concepts of eco-design. Here, we investigated the mechanical properties and morphologies of low density polyethylene (LDPE)/bamboo flour (BF) composites that were modified with polyethylene-graft-maleic anhydride (PE-g-MA) and glycerol. Scanning electron microscopy (SEM) and tensile tests of the composites demonstrated poor adhesion between the filler and matrix. Contact angle measurement showed that the surface of LDPE was modified by the presence of the load. The thermal stability of the composites was studied by measuring the oxidation induction time (OIT). Preliminary bacterial penetration tests were performed using culture inoculums of E. coli and S. aureus to investigate the natural antibacterial and bacteriostatic properties attributed to bamboo. Furthermore, bamboo may have interesting antioxidant activity with potential for use in food packaging applications.
\end{abstract}

Keywords: composites materials, thermal behavior, oxidation

\section{Introduction}

Materials design is a modern science that incorporates materials engineering with product design. According to Datschefski ${ }^{1}$, biothinking means looking at the world as a single system and developing new techniques derived from ecology to apply to sustainable design.

In this context, bamboo has shown great potential. Bamboo has accompanied human development since the beginning of technological progress, providing shelter, food, household utensils and other artifacts. In the East, it is known as the plant of a thousand uses due to its excellent physical, chemical and mechanical characteristics ${ }^{1}$.

Bamboo belongs to the grass family and it takes little time to be renewed, producing stems asexually for years without replanting. Bamboo plantations benefit the community because, apart from allowing the infiltration of rain into the soil, they help control erosion, sedimentation and recovery of carbon dioxide from the atmosphere ${ }^{2}$.

Bamboo can be a viable alternative of sustainable material for application in industrial design. One example that is worth mentioning is the work of Biswas et al. ${ }^{3}$. In this work, bamboo fiber-reinforced epoxy matrix composites were fabricated and filled with different weight proportions of red mud, a solid waste generated in alumina

*e-mail: eayres.pu@ hotmail.com plants. The mechanical properties of these composites were evaluated and then compared with glass-epoxy composites. This comparative study indicated that, although the bamboo-based composites exhibited relatively inferior mechanical properties, their erosion wear performance was better than that of the glass-fiber reinforced composites. In another study, Liu et al. ${ }^{4}$ used a treatment with $\mathrm{HNO}_{3}-\mathrm{KClO}_{3}$ and sulfuric acid hydrolysis to extract bamboo cellulose crystals (BCCs) to produce glycerol plasticized starch composites. The tensile strength and Young's modulus of starch/BCC composite films (SBC) were enhanced by the incorporation of the crystals due to reinforcement of the BCCs and a reduction in water uptake. BCCs at the optimal $8 \%$ loading level exhibited a higher reinforcing efficiency for plasticized starch plastic than any other loading level.

According to $\mathrm{Okubo}^{5}$, it is difficult to extract fibers with the superior mechanical properties of bamboo. Bamboo fiber is often brittle when compared with other natural fibers because they have a high percentage of lignin (approximately 32\%). In this work, the steam explosion technique was applied to extract fibers from raw bamboo trees. An additional process of mechanically rubbing the bundles was necessary to completely remove the lignin from the surface of the fibers, in order for the bamboo to function as reinforcement for plastics. 
Similar to others studies ${ }^{6,7}$, the present work used bamboo flour instead of extracted fibers to produce composites. Bamboo composites prepared in this way could be presented as a more viable alternative for the development of design products.

Recently there has been discussion about the antimicrobial activity in bamboo fiber ${ }^{8}$. Alves et al. ${ }^{9}$ stated that bamboo fiber contains a natural anti-bacterial agent called "Bamboo Kun". According to the authors, this statement was validated by the association of the inspection of textiles from Japan.

In a reality where concerns about the environment are increasingly present, research on the use of materials of a renewable nature are justified. In this paper, bamboo has been presented as a viable alternative for the design of composites. Earlier studies on bamboo-filled composites focused on the reinforcement of resultant composites ${ }^{10,11}$. However, the analysis of thermal oxidative behavior in addition to preliminary antimicrobial studies of bamboo composites have been less studied.

\section{Experimental}

\subsection{Materials}

Bamboo flour (BF) was obtained by grinding samples of bamboo Phyllostachys Heterocycla, aged 3 years and collected on Bambuzeria Cruzeiro do Sul-Bamcrus (Brazil). Samples were ground using sandpaper in carpentry and passed through 100-mesh screen to select the final grains.

Because wood undergoes degradation above $200{ }^{\circ} \mathrm{C}$, low density polyethylene (LDPE) (Braskem-Brazil) was used as matrix due to its low processing temperature. Polyethylene-graft-maleic anhydride (PE-g-MA) from Crompton (Brazil) was used in some samples to circumvent the large difference in surface polarity between the hydrophilic bamboo fiber and the hydrophobic polymer. Glycerol from Synth was used as a plasticizer to facilitate the processing of the composite. All chemicals were used in the condition in which they were received, without any pretreatment.

\subsection{Preparation of composites}

First, the reagents were mixed together in a torque rheometer (Haake PolyDrive Mixer manufactured by Thermo Fischer Scientific) at $110{ }^{\circ} \mathrm{C}$ with rotor speed of $40 \mathrm{rpm}$ for 10 minutes. Films were obtained using the

Table 1. Formulation of the composites (all values in weight percentage).

\begin{tabular}{ccccc}
\hline Sample & LDPE & Bamboo & PE-g-MA & Glycerol \\
\hline 0000 & 100 & $* * *$ & $* * *$ & $* * *$ \\
5000 & 95 & 5 & $* * *$ & $* * *$ \\
5300 & 92 & 5 & 3 & $* * *$ \\
5500 & 90 & 5 & 5 & $* * *$ \\
5003 & 92 & 5 & $* * *$ & 3 \\
5303 & 89 & 5 & 3 & 3 \\
5305 & 87 & 5 & 3 & 5 \\
\hline
\end{tabular}

conventional hot-press method at $110{ }^{\circ} \mathrm{C}$ for 5 minutes under $2 \mathrm{MPa}$ of pressure. Table 1 lists the samples prepared.

\subsection{Characterization of composites}

\subsubsection{Mechanical properties}

Pure LDPE (control) and composite specimens were characterized for their tensile properties, such as Young's modulus, tensile stress and elongation at break, using an Instron testing machine (model EMIC 3000) with a load cell of $200 \mathrm{~N}$. Tensile properties were characterized according to ASTM D-638; at least five specimens were tested to obtain the average values. A crosshead speed of $25 \mathrm{~mm} / \mathrm{min}$ and a gage length of $50 \mathrm{~mm}$ were used.

\subsubsection{Contact angle measurement}

A DIGIDROP-DI (GBX Instruments) goniometer was used to perform contact angle measurements. This system is equipped with a CCD camera connected to a computer and an automatic liquid dispenser. The contact angle was determined by placing a $10 \mu \mathrm{L}$ drop of water on the surface of the composite film $(2 \mathrm{~cm} \times 2 \mathrm{~cm})$ using a syringe and the image was immediately sent via the CCD camera to the computer for analysis. The results represent an average angle between the right and left angles. Three consecutive measurements were made at room temperature using the Surface Energy mode of the software, which allows direct measurement of the contact angle in degrees.

\subsubsection{Oxidation inductive time $\left(\mathrm{OIT}_{\text {air }}\right)$}

The sample was heated in a DSC instrument up to $200{ }^{\circ} \mathrm{C}$ at a rate of $20^{\circ} \mathrm{C} / \mathrm{min}$. After an isotherm of 5 minutes at $200{ }^{\circ} \mathrm{C}$, the atmosphere was switched from helium to synthetic air and the isotherm was maintained for another 30 minutes.

\subsubsection{Scanning electron microscopy (SEM)}

Scanning electron microscopy (SEM) (SHIMADZU model SSX 550) was employed to observe the cryogenic fracture surfaces. The samples taken from the fracture parts were coated with gold for 2 minutes prior to SEM observation.

\subsubsection{Penetration testing for microorganisms}

For the determination of bacterial penetration ability, small samples of pure polyethylene film (control) and the composite were sterilized with gamma rays (25 Grays). These samples were placed in sterile agar plates so that the entire bottom surface of the film came into contact with the agar. The upper surface of the film was contaminated with $25 \mu \mathrm{L}$ of overnight culture inoculums of E. coli (ATCC 25922) and $S$. aureus (ATCC 25923). The plates were then incubated at $37^{\circ} \mathrm{C}$ for 24 hours. The films were subsequently removed from the agar and examined for colony growth.

\section{Results and Discussion}

Stress-strain curves determined by tensile tests of the composites are shown in Figure 1, and the mechanical properties derived from these curves are listed in Table 2. 
Compared to neat LDPE, reinforcement with bamboo flour decreased the tensile strength and elongation at break, whereas the elastic modulus increased. These results could be due to the poor adhesion of bamboo fibers in the matrix as well as their lack of homogeneity within the matrix. In this way, the load acts as a defect rather than a reinforcement and does not absorb stresses efficiently or avoid the propagation of cracks.

The effect of plasticizer (glycerol) on mechanical properties can be observed by comparing composite 5000 with composite 5003. As expected, the addition of glycerol increased the elongation at break, but decreased the Young's modulus and the tensile strength. Glycerol also enhanced the processing of composites, but was not effective in improving their mechanical properties.

When comparing composite 5000 with composite 5300 , that the addition of PE-g-MA leads to a slight increase in the tensile strength, elongation at break and Young's modulus. This could be due to better compatibility of the fibers with the matrix. In the case of composite 5500, as the PE-g-MA content was increased to $5 \%$ all mechanical properties increased when compared with composite 5300, indicating that the composite was improved by the addition of PE-g-MA.

Furthermore, despite a slight increase in the tensile strength of composite 5303 when compared with composite 5003 , it can be observed that the use of glycerol along with PE-g-MA leads to a reduction in the mechanical properties of composites. Under the conditions of composite processing (temperature and pressure), some esterification reaction between maleic acid anhydride groups and glycerol could be occurring, thereby reducing the anhydride groups available to interact with the fibers. However, as noted by Tomka ${ }^{12}$, this reaction is not significant.

Unlike the slight improvements achieved in the performance of the composite due to the addition of PE-g-MA, Mohanty et al. ${ }^{13}$ reported that high density polyethylene (HDPE) composite loaded with $30 \mathrm{wt}$. (\%) of bamboo fiber and $2 \mathrm{wt}$. (\%) PE-g-MA exhibited an increase in tensile strength and tensile modulus of $18 \%$ and $279 \%$, respectively, when compared with untreated composites.

González et al. ${ }^{7}$ used a biorefinary strategy called autohydrolysis or hydrothermal processing, to circumvent the drawbacks caused by the hydrophilic nature of natural fibers. This technology is based on the utilization of liquid water at high temperature and pressure and thus is more environmentally friendly.

According to the authors, autohydrolysis removes extractives from the raw material while retaining lignin and autohydrolysed solids are expected to have improved compatibility with typical polymer matrices.
Wettability revealed that the hydrophilic character of the film surface increased due to the presence of polar bamboo fibers. The water contact angle decreased significantly in composite film tests, as illustrated in Figure 2.

These results emphasized that the hydroxyl and other polar groups located in the branched heteropolysacharides in bamboo fibers increased the wettability of LDPE. Hydroxyl groups form hydrogen bonds inside the macromolecule itself (intra-molecular) and between other cellulose macromolecules (inter-molecular) as well as with hydroxyl groups from the air ${ }^{14}$. In this context, it is possible that glycerol can form hydrogen bonds with the hydroxyl groups in the fibers, further increasing the wettability of the surface.

The incompatibility of components is also responsible for the poor thermal properties of films. OIT is a standardized test performed by differential scanning calorimetry (DSC) that measures the level of stabilization of the material being tested. One of the most common tests to determine the oxidative induction time of polyolefins by DSC is ASTM

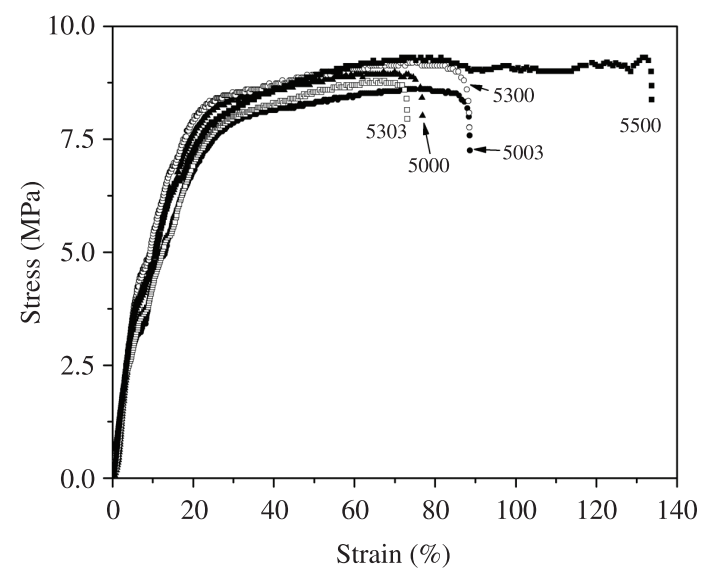

Figure 1. Stress-strain curves for the LPDE/bamboo composites. $(5000=\mathrm{LDPE}+5 \%$ bamboo flour $; 5003=\mathrm{LDPE}+5 \%$ bamboo flour $+3 \%$ glycerol; $5303=\mathrm{LDPE}+5 \%$ bamboo $+3 \%$ PE-g-MA $+3 \%$ glycerol; $5300=\mathrm{LDPE}+5 \%$ bamboo flour $+3 \%$ PE-g-MA; $5500=$ LDPE $+5 \%$ bamboo flour $+5 \%$ PE-g-MA).

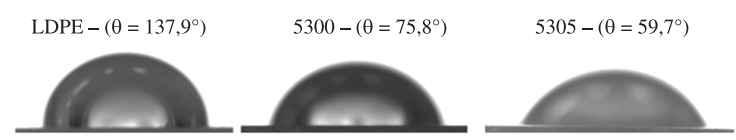

Figure 2. Contact angle measurements: pure LDPE $(\theta=137.90)$, sample $5300(\theta=75.80)$ and sample $5305(\theta=59.70)$. $(5300=\mathrm{LDPE}+5 \%$ bamboo flour $+3 \%$ PE-g-MA and $5305=5 \%$ bamboo flour $+3 \%$ PE-g-MA $+5 \%$ glycerol).

Table 2. Mechanical properties of pure polyethylene and composites, $\sigma=$ tensile strenght, $\varepsilon=$ elongation at break and $E=$ elastic modulus.

\begin{tabular}{ccccccc}
\hline & $\mathbf{0 0 0 0}$ & $\mathbf{5 0 0 0}$ & $\mathbf{5 0 0 3}$ & $\mathbf{5 3 0 3}$ & $\mathbf{5 3 0 0}$ & $\mathbf{5 5 0 0}$ \\
\hline$\sigma(\mathrm{MPa})$ & $10 \pm 0.5$ & $9.2 \pm 0.4$ & $8.4 \pm 0.4$ & $8.9 \pm 0.3$ & $9.4 \pm 0.3$ & $9.5 \pm 0.3$ \\
$\varepsilon(\%)$ & $230 \pm 12$ & $78 \pm 8$ & $88 \pm 9$ & $73 \pm 8$ & $90 \pm 9$ & $128 \pm 10$ \\
$\mathrm{E}(\mathrm{GPa})$ & $67 \pm 3$ & $91 \pm 10$ & $78 \pm 7$ & $72 \pm 5$ & $93 \pm 3$ & $89 \pm 8$ \\
\hline
\end{tabular}

$(0000=$ pure LDPE; $5000=$ LDPE $+5 \%$ bamboo flour; $5003=$ LDPE $+5 \%$ bamboo flour $+3 \%$ glycerol $; 5303=$ LDPE $+5 \%$ bamboo $+3 \%$ PE-g-MA $+3 \%$ glycerol; $5300=\mathrm{LDPE}+5 \%$ bamboo flour $+3 \%$ PE-g-MA; $5500=\mathrm{LDPE}+5 \%$ bamboo flour $+5 \%$ PE-g-MA $)$. 
D 3895 - 07. To perform this method, the sample must be heated under inert gas (argon), which is then switched to an oxygen atmosphere once the desired test temperature has been reached. The time to onset of an exothermic oxidation peak determines the induction time for oxidation.

The OIT test in this study was performed in synthetic air instead of oxygen and therefore was termed OIT air $^{\text {. }}$ This procedure facilitates the operation and minimizes possible damage to the DSC instrument. Although the measurements were reproducible, the curves representative of DSC (Figure 3) are attenuated, and the thermal events are not well defined, likely due to the atmosphere used. Nevertheless we observed that the OIT $_{\text {air }}$ values, calculated according to Schmid ${ }^{15}$, for pure LDPE (sample 0000) and composite without compatibilizer (sample 5000) were similar (0.9 minutes). Thermo-oxidation started at the temperature of the LDPE-rich phase. This result might be due to the poor interface between LDPE and bamboo flour, as indicated by their mechanical properties.

On the other hand, the composite with PE-g-MA (sample 5500) showed a high value for oxidation induction time (5.8 minutes) compared to LDPE. The increased compatibility between the phases of the composite was responsible for the increase in thermal properties and increase in induction time of the exothermic reaction.

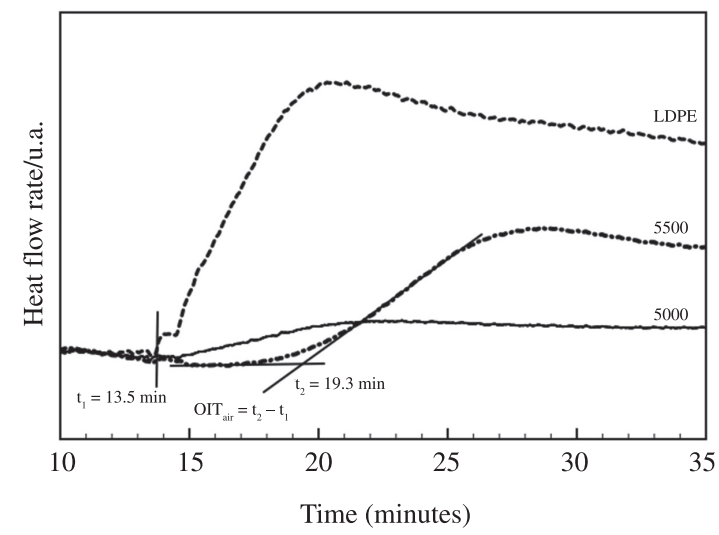

Figure 3. Oxidation induction times (OITs) for pure LDPE (sample 0000) and other composites (sample 5000 and 5500). $(5000=\mathrm{LDPE}+5 \%$ bamboo flour and $5500=5 \%$ bamboo flour $+5 \%$ PE-g-MA).

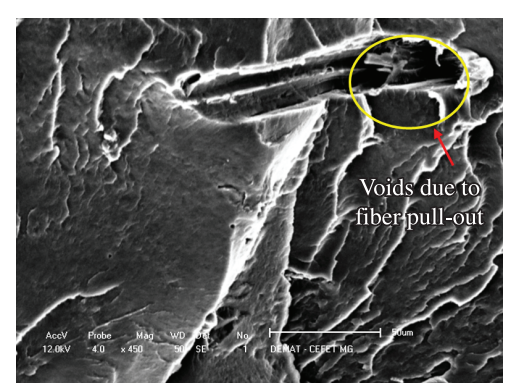

(a)

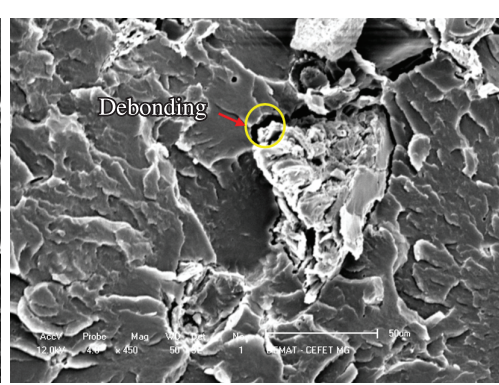

(b)
Unlike the results presented in Figure 3, Araújo et al. ${ }^{16}$ measured oxidation induction time in HDPE composites with Curaua fibers and found that oxidation induction times were analogous for composites with and without coupling agents.

The SEM micrographs of the fracture surface of composites 5000, 5003 and 5303 are shown in Figure 4.

In the micrograph of composite 5000 some voids can be observed, revealing that the fiber pulls out from the matrix due to poor interfacial adhesion between them. The lack of adhesion between the phases is also evident in the micrograph of composite 5003, which shows the debonding surface. The addition of glycerol seemed ineffective at improving the processing of the composite. The hydroxyl groups of glycerol likely interacted with the hydroxyl groups present in the chemical structure of the bamboo fibers. As a result, an increase in the polarity difference between the phases should have occurred that would have favored phase segregation. The micrograph of composite 5303 shows that the fibers are not embedded into the matrix. The SEM results confirmed the poor mechanical properties of the composites. The stress transfer ability at the fiber-matrix interface of wood fiber composites is known to affect its mechanical properties $^{17}$. The lack of adhesion between the fiber and matrix potentially limited the stress transfer efficiency at the fiber-matrix interface. Therefore, further improvements in adhesion need to be made.

Interesting results were found by Liu et al. ${ }^{6}$ in their study of HDPE-based composites that were filled with bamboo flour. For example, when 3.8 wt. (\%) of PE-g-MA was coupled with 1.9 wt. (\%) of semi-crystalline maleated ethylene/propylene elastomer (sEPR-g-MA) and used as a combined modifier, pull-out or breakage of fibers was not observed and the interfacial adhesion appeared strong even when working at an HDPE/BF ratio of 60/40 (wt/wt).

In an attempt to verify the antimicrobial activity of bamboo, Gram-positive and Gram-negative bacteria were used to carry out a preliminary microbe penetration test. There was no penetration of bacteria through the films in the composite (sample 5000) or in the control (pure polyethylene). Thus, the penetration testing of bacteria was inconclusive. Because the bacteria were in aqueous solution, the high hydrophobicity of polyethylene may have prevented the growth of colonies rather than the natural antibacterial

Figure 4. (a) SEM of the cryofracture surface of the composite 5000. (5000 = LDPE $+5 \%$ bamboo flour $)$. Magnification: $450 \mathrm{X}$ and bar $=50 \mu \mathrm{m}$; (b) SEM of the cryofracture surface of composite 5003. (5003 = LDPE + 5\% bamboo flour + 3\% glycerol). Magnification: $450 \mathrm{X}$ and bar $=50 \mu \mathrm{m}$; (c) SEM of the cryofracture surface of the composite 5303. (5303 = LDPE $+5 \%$ bamboo flour $+3 \%$ PE-g-MA $+3 \%$ glycerol). Magnification: $450 \mathrm{X}$ and $\mathrm{bar}=50 \mu \mathrm{m}$. 
properties attributed to bamboo fibers. On the other hand, the presence of bamboo increased the hydrophilicity of the polyethylene film surface, as demonstrated by the contact angle measurements $\left(\theta=137.9^{\circ}\right.$ for pure LDPE and $75.8^{\circ}$ or $59.7^{\circ}$ for composites), providing more favorable conditions for bacteria to reach the culture medium. These results indicate that further tests need to be performed.

The antimicrobial activity in bamboo shoot extracts has been questioned by others ${ }^{18,19}$. Yang et al. ${ }^{18}$ tested the antibacterial efficacy of bamboo charcoal/polyoxometalates composites and found that, unlike the composites, pure bamboo charcoal did not show any antibacterial activity. The strong antibacterial activity of the composites was attributed to the highly negative charge of the polyoxometalates.

Park et al. ${ }^{19}$ did not identify any antibacterial activity in their study analyzing the functional properties of solvent extracts from bamboo shoots. As cited by these authors, the antimicrobial activity of bamboo stem and leaf extracts has been reported by others but was not identified by their methods. However, they did find significant antioxidant capacity of bamboo extracts that correlated with their phenolic content.

LDPE has points in its chain that are susceptible to thermal oxidation, specifically the hydrogen atoms attached to the tertiary and secondary carbon atoms. The potential antioxidant ability of bamboo could protect LDPE against thermal oxidation. Monitoring this behavior can be accomplished by OIT measurements, which have been previously performed ${ }^{20}$. In this case, the authors prepared polymeric antioxidants to protect polypropylene (PP) from degradation by thermal oxidation. The ability of the synthesized polymers to act as antioxidants was characterized by an increase in the OIT of PP. The same trend was observed in our results, shown in Figure 3 where pure LDPE (0000) is compared with the composite with the compatibilizer (5500). The increase in OIT of the composite suggests that LDPE is stabilized by the addition of bamboo.

Plastics are one of the most important materials used in food packaging due to their advantages over other materials, and polyethylene (PE) is one of the most commonly used synthetic polymers ${ }^{21}$.

\section{References}

1. Datschefski E. The Total Beauty of Sustainable Products. New York: Rotovision; 2001.

2. Pereira MAR and Beraldo AL. Bambu de Corpo e Alma. Bauru: Canal 6 Editora; 2007. 240 p.

3. Biswas $\mathrm{S}$ and Satapathy A. A comparative study on erosion characteristics of red mud filled bamboo-epoxy and glass-epoxy composites. Materials and Design. 2010; 31(4):1752-67. http:// dx.doi.org/10.1016/j.matdes.2009.11.021

4. Liu D, Zhong T, Chang, PR, Li K and Wu Q. Starch composites reinforced by bamboo cellulosic crystals. Bioresource Technology. 2010; 101(7):2529-36. PMid:20015636. http:// dx.doi.org/10.1016/j.biortech.2009.11.058

5. Okubo K, Fujii T and Yamamoto Y. Development of bamboo-based polymer composites and their mechanical
The combination of renewable resources with plastic commodity products in order to reduce the waste associated with their use is particularly relevant to packaging applications $^{21}$.

Fendler et al. ${ }^{22}$ have already reported an increase in the oxygen and limonene barrier properties of HDPE composites containing varying amounts of highly purified alpha cellulose fibers as a filler and maleic anhydride-grafted polyethylene as a compatibilizer.

The potentially natural antimicrobial and antioxidant properties of bamboo fibers could lead to composites with enhanced potential in food packaging applications. However, further studies investigating the barrier properties of these composites and the antimicrobial activity of bamboo are required.

\section{Conclusion}

In this study, we investigated the effects of adding bamboo flour into an LDPE matrix. The results from SEM and mechanical properties showed that further improvements need to be made in the adhesion between phases. Wettability tests revealed an improvement in the hydrophilicity of the surface due to the presence of polar bamboo fibers. The composite using PE-g-MA demonstrated a high value for oxidation induction time when compared with pure LDPE. The penetration testing of bacteria was inconclusive, and further tests are required. The results of the oxidation induction time from DSC suggest that some antioxidant activity of bamboo exists. The possibility of natural antimicrobial and antioxidant properties of bamboo fibers could lead to composites with enhanced potential in food packaging applications.

\section{Acknowledgements}

The authors acknowledge financial support from Coordination of Improvement of Senior Staff (CAPES) and the Microscopy Laboratory of CEFET-MG for the SEM images.

properties. Composites Part A. 2004; 35:377-83. http://dx.doi org/10.1016/j.compositesa.2003.09.017

6. Liu H, Wu Q, Han G, Yao F, Kojima Y and Suzuki S. Compatibilizing and toughening bamboo flour-filled HDPE composites: Mechanical properties and morphologies. Composites Part A. 2008; 39:1891-1900. http://dx.doi. org/10.1016/j.compositesa.2008.09.011

7. González D, Santos V and Parajó JC. Manufacture of fibrous reinforcements for biocomposites and hemicellulosic oligomers from bamboo. Chemical Engineering Journal. 2011; 167(1):278-87. http://dx.doi.org/10.1016/j. cej.2010.12.066

8. Gomathi C. Study of antimicrobial behavior of socks from bamboo. Green Earth Bamboo; 2010.Available from: <http:// www.greenearthbamboo.com/Articles.asp? $\mathrm{ID}=132>$. Access in: 19/08/2010. 
9. Alves GJS, Raphaelli N and Fangueiro R. Desenvolvimento sustentável na indústria têxtil: estudo de propriedades e características de malhas produzidas com fibras biodegradáveis. In: Anais do XXII Congresso Nacional de Técnicos Têxteis - VIII Fenatêxtil; 2006; Recife. Recife; 2006.

10. Rao KMM and Rao KM. Extraction and tensile properties of natural fibers: Vakka, date and bamboo. Composite Structures. 2007; 77:288-95. http://dx.doi.org/10.1016/j. compstruct.2005.07.023

11. Wong KJ, Zahi S, Low KO and Lim CC. Fracture characterization of short bamboo fibre reinforced polyester composites. Materials and Design. 2010; 31:4147-54. http:// dx.doi.org/10.1016/j.matdes.2010.04.029

12. Tomka I. Polymer mixture for producing film. US patent 5314934. 1994 May 24.

13. Mohanty S and Sanjay KN. Short Bamboo Fiber-reinforced HDPE Composites: Influence of Fiber Content and Modification on Strength of the Composite. Journal of Reinforced Plastics and Composites. 2010; 29(14):2199-210. http://dx.doi. org/10.1177/0731684409345618

14. Joseph K, Toledo RDF, James B, Thomas S and Carvalho LH. A review o sisal fiber reinforced polymer composites. Revista Brasileira de Engenharia Agrícola e Ambiental. 1999; 3:367-79.

15. Schmid M and Affolter S. Interlaboratory tests on polymers by differential scanning calorimetry (DSC): determination and comparison of oxidation induction time (OIt) and oxidation induction temperature (OIT). Polymer Testing. 2003; 22:419-28. http://dx.doi.org/10.1016/S0142-9418(02)00122-8

16. Araújo JR, Waldman WR and De Paoli MA. Thermal properties of high density polyethylene composites with natural fibres: Coupling agent effect. Polymer Degradation and Stability. 2008; 93:1770-75. http://dx.doi.org/10.1016/j. polymdegradstab.2008.07.021

17. Amgren KM and Gamstedt KE. Caracterization of interfacial stress transfer ability by dynamic mechanical analysis of cellulose fiber based composite materials. Composite Interfaces. 2010; 17(9):845-61. http://dx.doi. org/10.1163/092764410X539235

18. Yang FC, Wu KH, Lin WP and Hu MK. Preparation and antibacterial efficacy of bamboo charcoal/polyoxometalate biological protective material. Microporous and Mesoporous Materials. 2009; 118:467-72. http://dx.doi.org/10.1016/j. micromeso.2008.09.026

19. Park EJ and Jhon DY. The antioxidant, angiotensin converting enzyme inhibition activity, and phenolic compounds of bamboo shoot extracts. LWT-Food Science and Technology. 2010; 43:655-59.

20. Xue B, Ogata K and Toyota A. Synthesis of polymeric antioxidants based on ring-opening metathesis polymerization (ROMP) and their antioxidant ability for preventing polypropylene (PP) from thermal oxidation degradation. Polymer Degradation and Stability. 2008; 93:347-52. http:// dx.doi.org/10.1016/j.polymdegradstab.2007.12.001

21. Tajeddin B. Rahman RA and Abdulah LC. The effect of polyethylene glycol on the characteristics of kenaf cellulose/ low-density polyethylene biocomposites. International Journal of Biological Macromolecules. 2010; 47:292-97. PMid:20417660. http://dx.doi.org/10.1016/j. ijbiomac.2010.04.004

22. Fendler A, Villanueva MP, Gimenez E and Lagaron JM. Characterization of the barrier properties of composites of HDPE and purified cellulose fibers. Cellulose. 2007; 14:427-38. http://dx.doi.org/10.1007/s10570-007-9136-x 